\title{
A Graduação Médica e a Prática Profissional na Perspectiva de Discentes
}

\author{
Undergraduate Medical Education and \\ Professional Practice from a Student's \\ Perspective
}

Marcos Augusto Filisbino ${ }^{I}$ Vardeli Alves de Moraes ${ }^{I}$

\section{PALAVRAS-CHAVE: \\ - Educação Médica \\ - Internato; \\ - Discentes; \\ - Diretrizes Curriculares \\ Nacionais.}

\section{KEYWORDS:}

- Medical Education;

- Internship;

- Students;

- National Curriculum Policy.

Recebido em: 13/06/2013

Aprovado em: 12/12/2013

\begin{abstract}
RESUMO
Estudo transversal quantitativo descritivo observacional, realizado com discentes do internato da Faculdade de Medicina da Universidade Federal de Goiás. Objetivos: Conhecer a expectativa de prática profissional de discentes do internato e observar possíveis dissonâncias em relação ao perfil do discente preconizado pelas Diretrizes Curriculares Nacionais e projeto político-pedagógico da instituição. Metodologia: Foi utilizado um questionário distribuído aos 222 discentes do internato da instituição no ano de 2012. A amostra consta de 190 discentes, que correspondem a 85\% do universo de análise. A significância estatística foi calculada pelo Teste do Sinal. Resultados: O perfil sociodemográfico caracteriza discentes com idade média de 23,8 anos, solteiros, sendo que $66 \%$ pertencem às classes sociais A e B. O ideal do perfil de prática profissional demonstra que $84 \%$ pretendem ser especialistas, $96 \%$ desejam cursar residência médica, sendo estatisticamente significante ( $p=0,0001)$, e 70\% não pretendem, a priori, trabalhar na Estratégia Saúde da Família (ESF) ( $p=0,005)$. Conclusão: $O$ estudo demonstra discentes com perfil socioeconômico elevado, que pretendem ser especialistas, cursar residência médica e não veem a ESF como uma meta-fim.
\end{abstract}

\section{ABSTRACT}

Introduction: The aim of this research is to identify, in terms of professional practice, the ideal internship students in the Medical School of the Federal University of Goiás (UFG) and to observe possible dissonances in relation to the graduate profile as advocated by the National Curriculum Guidelines and by the Political Pedagogical Project of this institution. Methods: In 2012, two hundred and twenty-two medical internship students of the institution received a survey questionnaire. The sample of this research consisted of one hundred and ninety research subjects, representing $85 \%$ of the sample universe. The statistical significance was calculated using the Sign Test. Results: The socio-demographic profile characterizes the students with an average age of 23.8 years old, unmarried, $66 \%$ of whom belong to social classes $A$ and B. The ideal profile of professional practice shows that $84 \%$ want to become specialists, whereas $96 \%$ want to engage in medical residency, which is statistically significant ( $p=0.0001$ ), and $70 \%$ do not intend to work with Family Health Strategy Programs $(p=0.005)$. Conclusion: This study shows that students with high socio-economic profile, who want to become specialists, undergo a medical residency program and do not see the Family Health Strategy as a professional goal. 


\section{INTRODUÇÃO}

O presente estudo é o produto de uma inquietação pessoal, motivada pelo desejo de conhecer o hiato existente entre o perfil dos futuros egressos preconizado pelas Diretrizes Curriculares Nacionais e pelo projeto político-pedagógico da instituição e o perfil pretendido e idealizado pelos discentes na fase final de sua graduação, correspondente ao período do internato.

$\mathrm{O}$ inconformismo gera ansiedade, aqui sublimada em energia que foi positivamente canalizada para esta pesquisa, cujos resultados serão salutares para implementar mudanças e correção de trajetórias na busca incessante de formatar um egresso com formação geral e humanística.

O curso médico da Faculdade de Medicina da Universidade Federal de Goiás (FM/UFG) é dividido em dois ciclos: o básico e o clínico, que inclui o internato ${ }^{1,2}$.

O internato é definido como o estágio curricular de treinamento em serviço, sob supervisão direta dos docentes, incluindo aspectos essenciais nas áreas básicas de Clínica Médica, Cirurgia, Pediatria, Ginecologia/Obstetrícia e Saúde Coletiva, devendo incluir atividades em todos os níveis de atenção (primária, secundária e terciária), com duração de dois anos ${ }^{1,3,4}$.

A influência da fragmentação cartesiana sobre o pensamento médico resultou no chamado modelo biomédico, que se tornou o marco referencial da medicina moderna. Essa visão reducionista provocou uma disjunção entre mente e corpo, entre sujeito e objeto. Tal modelo biologicista dividiu o ser humano, uno, em diversos órgãos e tecidos, que são estudados e tratados de forma isolada, com perda da visão holística ${ }^{5}$.

Seguindo a concepção reprodutivista da educação, o ensino médico tradicional perpetua o modelo biomédico, igualmente reducionista, focado na doença, procedimento centrado e dependente de tecnologia sofisticada e, portanto, forçosamente hospitalocêntrico, mantendo o modelo flexneriano. Esse modelo divide o curso médico em ciclo básico e profissional, é fragmentado em disciplinas que não se comunicam e é centrado no professor, com transmissão vertical do conhecimento, com predomínio de aulas expositivas e avaliação somativa ${ }^{3,6}$.

O modelo tradicional da medicina não consegue atender às necessidades de saúde da sociedade contemporânea em um mundo globalizado, o que gera uma insatisfação nas pessoas e cria um cenário propício às mudanças ${ }^{3,7}$.

Por essa razão, nas últimas quatro décadas, a educação médica, nesse contexto, tem sido objeto de grandes questionamentos e tem experimentado significativas mudanças, em nível tanto nacional quanto internacional, no sentido de uma formação que valorize o conhecimento geral e estimule o pensamento crítico e reflexivo ${ }^{6,8-10}$.
No plano internacional, a Conferência de Alma Ata (1978) orientou a educação médica para a estratégia da Atenção Primária, e as Conferências Mundiais de Educação Médica, em Edimburgo (1988 e 1993), reorientaram a educação médica em face das mudanças da prática profissional ${ }^{3}$.

No Brasil, na década de 1980, a promulgação da Constituição brasileira - que assegurou a saúde como direito de todos e dever do Estado, a criação e consolidação do Sistema Único de Saúde (SUS), com a proposta de universalidade, equidade, integralidade e participação social - e a sinergia das ações dos ministérios da Saúde e da Educação propiciaram a promulgação de políticas públicas com o objetivo de reorientar a formação de profissionais médicos segundo o modelo da integralidade e, assim, vir ao encontro das necessidades da população ${ }^{3,6}$.

Dentre as políticas de governo para a área da saúde, a implantação das Diretrizes Curriculares Nacionais para o Curso de Graduação em Medicina (Resolução CNE/CES nº 04/2001) é considerada um marco histórico na construção de um novo perfil do egresso dos cursos médicos que atenda às demandas e necessidades da sociedade ${ }^{9,11,12}$, estabelecendo um marco estruturante na construção de um novo paradigma para a educação desses profissionais, denominado Paradigma da Integralidade, que visa à orientação de formação profissional para impulsionar a efetivação dos princípios do SUS, adequando o perfil do egresso às demandas de saúde da população $0^{9,12-14}$.

De acordo com o artigo $3^{\circ}$ das DCN, "o curso de graduação em medicina tem como perfil do egresso o médico, com formação generalista, humanista, crítica e reflexiva" ${ }^{\prime, 12}$. Em seu projeto político-pedagógico, a FM/UFG contempla os princípios das DCN, incorporando ipsis litteris o seu artigo 3º, que conceitua o perfil do profissional a ser formado pelas instituições médicas brasileiras ${ }^{1,2,9,12}$. Na prática, porém, o que se percebe é que mudanças curriculares estão sendo insuficientes para remover as resistências ${ }^{15}$.

A falta de terminalidade do curso médico, a dissociação entre ensino e serviço, e a especialização precoce do estudante de Medicina têm postergado para a pós-graduação a formatação profissional que a graduação não consegue resolver ${ }^{16}$. Por isso, a residência médica, idealizada como uma meta-fim pela maioria dos egressos do curso médico, tem sido um problema para as escolas médicas ${ }^{17}$. $\mathrm{O}$ despreparo técnico-profissional do docente, aliado a um papel reprodutivista da ideologia dominante assumida pela universidade, forma uma relação docente/discente vertical, promovendo um reducionismo do discente, deixando-o desprovido de aspectos subjetivos, como a criatividade e o pensamento crítico reflexivo ${ }^{18}$. 
Em seu projeto pedagógico (dezembro de 2003), a FM/ UFG tem procurado romper com o "paradigma flexneriano", contemplando em seu bojo a (des)hospitalização e a (des)especialização $^{1,2}$.

A mudança nas práticas e na formação são dois lados de um mesmo movimento no sentido de atingir a atenção integral à saúde ${ }^{13}$. Percebe-se o quão difícil é implantar as necessárias e salutares mudanças, tendo em vista o que se presencia cotidianamente nessa instituição.

O objeto do presente trabalho é analisar as expectativas de prática profissional dos discentes do internato da FM/UFG, verificando se este tem sido modificado para atender às novas diretrizes curriculares, bem como ao projeto político-pedagógico institucional e, desta forma, vir ao encontro das reais necessidades da população $0^{1,6,12}$.

\section{OBJETIVOS}

\section{Objetivo geral}

Conhecer as expectativas de prática profissional dos discentes do internato da Faculdade de Medicina da Universidade Federal de Goiás.

\section{Objetivos específicos}

Conhecer o perfil sociodemográfico dos discentes do internato da Faculdade de Medicina da Universidade Federal de Goiás;

Observar possíveis consonâncias ou dissonâncias entre as expectativas de prática profissional desses discentes e o perfil do egresso preconizado nas Diretrizes Curriculares Nacionais e no projeto político-pedagógico da instituição.

\section{REFERENCIAL TEÓRICO}

Para compreender a educação médica no Brasil, é preciso remontar por um breve instante a sua origem, ocorrida em 1808, após a vinda da família real portuguesa para o Brasil, com a criação das duas primeiras faculdades de Medicina do País, uma em Salvador e outra no Rio de Janeiro, com a clara finalidade de satisfazer às demandas da corte portuguesa e da burguesia dominante, não levando em consideração as reais demandas da sociedade. Essas escolas médicas receberam, no seu início, influências das escolas alemã, com ênfase na pesquisa laboratorial, e francesa, de cunho anatomoclínico ${ }^{7,12,19}$

O século XX é marcado por duas fases distintas: a primeira metade é caracterizada pela criação de poucas escolas médicas, apenas dez; na segunda, há um período de crescimento desorganizado de faculdades de Medicina ${ }^{7,12}$.

No pós-guerra, por questões econômicas, o Brasil se aproximou em demasia dos Estados Unidos, importando muitos valores daquela cultura em diversos campos da atividade hu- mana em geral e das ciências médicas em particular, com a adoção do modelo "flexneriano", com consequente fragmentação dos saberes e desconexão dos ciclos básico e profissional, culminando numa prática médica hospitalocêntrica, hiperespecialista e centrada na doença ${ }^{6}$.

O modelo biomédico, como balizador da ciência médica do século $X X$, teve grande avanço em escala mundial, influenciando fortemente a formação de profissionais da área de medicina em todo o mundo ${ }^{5,18}$.

No início do século, Abraham Flexner, um educador formado na Universidade Johns Hopkins, foi convidado pela Fundação Carnegie, provavelmente por influência de seu irmão Simon Flexner, diretor e fundador da Fundação Rockefeller, para dirigir um programa de avaliação de educação médica nos Estados Unidos e Canadá, originando o relatório que leva o seu nome, o famoso Relatório Flexner, amplamente divulgado na Europa e na América Latina ${ }^{19}$.

No Brasil, sua repercussão foi tardia, na segunda metade do século XX, paralela à proliferação desordenada de escolas médicas, atingindo seu clímax no governo militar, quando foram criadas 35 escolas médicas entre 1966 e 1971. Da aproximação com o modelo americano resultou a criação de hospitais-escola, que eram simultaneamente cenários de prática e de pesquisa ${ }^{7,19}$

Com a abertura política na década de 1980 e a nova Constituição trazendo um avanço social importante, conceituando a saúde como um direito de todos e dever do Estado, nasce o Sistema Único de Saúde (SUS) como um movimento social contra-hegemônico que se contrapõe ao modelo biomédico vigente $^{11,14}$.

Tem início a mudança de paradigmas na área de educação médica, com a substituição do modelo biomédico (flexneriano) pelo paradigma da integralidade, que buscou desde o início o equilíbrio entre a excelência técnica e a relevância social. Segundo Kuhn, um novo modelo paradigmático deve preencher duas condições necessárias: solucionar problemas que o modelo anterior não conseguiu resolver e preservar os benefícios construídos pelo paradigma anterior. Essa transição terá uma longa trajetória, com idas e vindas, desconstruções e reconstruções ${ }^{7,19}$.

Vinte anos após a sua embriogênese, o SUS ainda é um sistema de saúde em processo de consolidação, que luta para garantir seus princípios de universalidade, equidade e participação social, gerando contradições com a fragmentação existente no setor privado, assim como ambiguidades no mundo do trabalho para os egressos do curso médico ${ }^{11}$.

Nesse contexto, foram construídas, no início da década passada, as Diretrizes Curriculares Nacionais (DCN) para os 
Cursos de Graduação em Medicina, cuja publicação se deu em 3 de janeiro de 2001 no Diário Oficial da União, consistindo em um referencial na formação do profissional médico do Brasil contemporâneo ${ }^{20-22}$.

Em seu artigo $3^{\circ}$, as $\mathrm{DCN}^{9}$ preconizam o seguinte perfil dos futuros egressos:

Médico com formação generalista, humanista, crítica e reflexiva capacitado para atuar pautado em princípios éticos, no processo saúde-doença em seus diferentes níveis de atenção, com ações de promoção, prevenção, recuperação e reabilitação à saúde, na perspectiva da integralidade da assistência, com senso de responsabilidade social e compromisso com a cidadania, como promotor da saúde integral do ser humano.(p.38)

Desde a homologação das DCN, as faculdades de Medicina brasileiras têm procurado incorporar em seus projetos pedagógicos os preceitos emanados pelas diretrizes. O projeto pedagógico não opera de per si as mudanças necessárias; é preciso implementá-las, ou seja, elas precisam sair do papel ${ }^{7}$.

Uma década após a sua publicação, o maior desafio é torná-las vivas, fazer o sonho se tornar realidade, pois há uma contradição entre os novos perfis de egressos requeridos pela sociedade e requisitados pelo SUS em consolidação e os perfis produzidos pelas escolas médicas brasileiras ${ }^{12}$.

Daí se entender que é fundamental uma cooperação mútua entre a instituição de ensino superior e o SUS para se mudar o perfil dos novos egressos, a fim de aproximar o projeto pedagógico das reais necessidades da população. É preciso desenvolver competências para se trabalhar na Atenção Básica, sendo necessária a (des)hospitalização do ensino médico, o que encontra forte resistência dos docentes formados no regime hospitalocêntrico pelo sistema tradicional ${ }^{2,11,23}$.

Um estudo realizado na Escola Superior de Ciências da Saúde (ESCS), no Distrito Federal, por meio de abordagem quali-quantitativa com amostra de 120 estudantes da graduação médica e recém-egressos da referida instituição, demonstrou a eficácia da incorporação de valores éticos preconizados nas DCN no perfil de formação do egresso da instituição ${ }^{24}$.

Uma pesquisa realizada na Faculdade de Medicina da Universidade Federal de Minas Gerais demonstrou o interesse precoce dos graduandos desse curso pela especialização ${ }^{25}$.

Outra pesquisa conduzida nessa mesma instituição com 738 graduandos de Medicina indicou que apenas 15,4\% gostariam de prosseguir a carreira profissional na Atenção Básica, sendo que apenas $1 \%$ dos pesquisados gostaria de ser generalista, resultado consistente com a literatura mundial ${ }^{26}$. Uma pesquisa realizada na Austrália demonstrou que a progressão na carreira e o reconhecimento são altamente valorizados pelos egressos dos cursos médicos, e isto não está associado ao exercício da prática médica generalista ${ }^{27}$.

A educação médica tem sido objeto de crítica quanto a sua capacidade de cumprir as finalidades gerais dos projetos político-pedagógicos no sentido de desenvolver no egresso a capacidade crítico-reflexiva e a abordagem criativa e subjetiva no trato com os pacientes ${ }^{21}$.

A concepção abrangente da educação como aprender a conhecer, a fazer, a ser e a viver juntos tem sido incorporada às diretrizes curriculares nacionais e, em particular, na área médica $^{13,25}$.

Uma visão da mesma realidade sob um prisma diferente tem apontado mudanças na formação profissional dos discentes nas escolas médicas com a utilização dos processos de problematização do ensino-aprendizagem, questionando-se, porém, a eficácia real dessas mudanças na construção de um novo perfil de formação do egresso em face da complexidade que tal formação envolve $\mathrm{e}^{4,12,28}$.

As novas demandas e necessidades da população na área da saúde têm gerado contradições entre o paradigma flexneriano - com fragmentação do saber, centrado na doença, hospitalocêntrico - e o paradigma da integralidade, que visa à construção social da saúde com foco na promoção de saúde ${ }^{5}$.

No campo educacional, essa dualidade se expressa numa tensão permanente entre duas concepções pedagógicas antagônicas: de um lado, a concepção tradicional hegemônica, centrada no professor e baseada na transmissão vertical de informações; de outro lado, a concepção crítico-reflexiva, centrada no aluno e na qual o conhecimento é construído com base em técnicas problematizadoras no processo de ensino-aprendizagem (Brasil, 2001) - isto é preconizado nas DCN do curso de Medicina (artigo $\left.3^{\circ}\right)^{9}$, as quais objetivam construir um perfil profissional do egresso segundo as necessidades reais da população, gerando competências e habilidades para trabalhar no SUS com resolutividade ${ }^{7,12,14,29}$.

Em 2012, no Brasil, foram formados 16.227 médicos, perfazendo 388.015 profissionais, dos quais 55\% são especialistas, segundo registros do Conselho Federal de Medicina (CFM). Portanto, há 1,23 especialista para cada generalista, distribuídos em 53 especialidades médicas reconhecidas pelo $\mathrm{CFM}^{10}$.

\section{MÉTODOS}

Trata-se de um estudo descritivo quantitativo, sendo a população-alvo os graduandos do internato da Faculdade de Medicina da Universidade Federal de Goiás (FM/UFG) do ano letivo de 2012. 
Seguindo normas da instituição (FM/UFG), o projeto de pesquisa foi apresentado ao Departamento de Ginecologia e Obstetrícia, sendo previamente analisado por uma Comissão de Apoio à Pesquisa (GAP), constituída por três docentes desse departamento.

O instrumento utilizado na coleta de dados foi um questionário composto por duas partes. A primeira abordou o perfil sociodemográfico dos discentes, constando de oito perguntas fechadas e duas semiabertas. A segunda parte continha 12 perguntas fechadas para verificar o ideal de perfil profissional dos referidos estudantes. Foi elaborado um questionário piloto, que foi detalhadamente revisado pela GAP. Posteriormente, realizou-se um pré-teste para validação do questionário, aplicando-o a um grupo de estudantes do ciclo profissional da FM/UFG. Na oportunidade, foram acatadas sugestões de reformulação de duas perguntas.

O projeto foi aprovado em Assembleia Departamental em janeiro de 2012, e em fevereiro desse mesmo ano o projeto foi encaminhado ao Hospital das Clínicas da FM/UFG para obtenção de anuência do diretor-geral. Cumprindo a Resolução 196 do Conselho Nacional de Saúde, o projeto foi encaminhado ao Comitê de Ética em Pesquisa (CEP) do Hospital das Clínicas da UFG, via Plataforma Brasil, em março de 2012, nº do Sisnep CAAE: 01273512.3.0000.5078, tendo sido obtida a aprovação do CEP em 26 de abril de 2012 com o parecer consubstanciado do CEP no 15.661 (Anexo B). Somente após a aprovação pelo referido CEP teve início a coleta de dados propriamente dita.

Foi enviado a cada um dos sujeitos de pesquisa, em seu respectivo cenário de prática, um envelope, sem identificação do aluno, contendo: uma carta-convite da instituição esclarecendo o caráter voluntário da pesquisa, duas vias do Termo de Consentimento Livre e Esclarecido (TCLE) e uma via do questionário. Uma vez preenchidos, esses documentos eram recolocados no envelope e devolvidos ao pesquisador, ficando uma via do TCLE em poder do participante. Foi dada uma nova oportunidade aos que não responderam ao questionário, após 30 dias de sua distribuição. A estes foram enviados e-mails com os mesmos materiais distribuídos de forma impressa, para responderem por via eletrônica. Os dados foram colhidos de maio a agosto de 2012. Todos os participantes foram orientados a preencher inicialmente $\mathrm{o}$ TCLE e a assiná-lo para em seguida responder ao questionário.

Como critério de inclusão, foi utilizada a assinatura do TCLE e a devolução do questionário respondido pelo sujeito de pesquisa. E como critério de exclusão, os discentes que não assinaram o TCLE e/ou não responderam ao questionário.
Para análise dos resultados, utilizou-se a estatística descritiva, mediante a distribuição de frequências simples e percentuais, com cálculo de intervalos de confiança em planilha Excel.

Para validação da hipótese de pesquisa, empregou-se o Teste do Sinal (Teste t), que avalia duas variáveis independentes.

O universo de análise da pesquisa compreendeu estudantes de Medicina da FM/UFG inseridos no último ciclo da graduação do ano letivo de 2012. A população estudada constou de 222 alunos - em listagem fornecida pela secretaria do curso de Medicina -, que cumpriam os dois últimos anos da graduação, estando todos eles no internato em 2012, sendo que $50 \%$ deles cursavam o quinto ano e os outros $50 \%$ estavam no sexto e último ano da graduação. Todos os sujeitos envolvidos na pesquisa cumpriam o internato no período de coleta dos dados para o estudo, em diferentes cenários de prática.

\section{RESULTADOS}

A amostra constou de 190 alunos, que preencheram os critérios de inclusão, representando $85 \%$ do universo de análise, sendo 103 do sexto ano (54\%) e 87 do quinto ano (46\%). Houve predominância do sexo masculino $(53,7 \%)$ em relação ao sexo feminino $(46,3 \%)$.

O perfil socioeconômico apresenta predominância de solteiros $(94,7 \%)$, com média de idade de 23,8 anos, sem filhos $(98 \%)$, sendo a terça parte $(34 \%)$ pertencente a famílias da classe A, com renda superior a 20 salários mínimos; (31,6\%) estão na classe B, com renda entre 11 e 20 salários mínimos (Tabela 1). Dos entrevistados, 133 (70\%) afirmam ter carro próprio. Em relação a parentes médicos, 117 discentes (61,5\%) afirmam ter algum parente médico na família, e 32 são filho(a) s de médico(a), correspondendo a $16,8 \%$ da amostra.

Em relação ao perfil do ideal de prática profissional dos discentes (Tabela 2), a pesquisa revelou que 159 (83,7\%) dos futuros egressos, estatisticamente significante $(p=0,0001)$, desejam ser especialistas, ao passo que $23(12,1 \%)$ expressam o desejo de ser médicos generalistas. Do total de pesquisados, $183(96,3 \%)$ afirmam a pretensão de fazer residência médica, com significância estatística ( $p=0,0001)$, e apenas $2(1,05 \%)$ não desejam fazer residência, sendo que 5 (2,7\%) discentes estão indecisos quanto a cursar ou não a residência médica. Dentre os alunos que desejam fazer residência médica, 111 (58,4\%) já elegeram a especialidade a ser cursada, demonstrando uma tendência precoce de especialização durante a graduação, sendo estatisticamente significante $(\mathrm{p}=0,005)$. Após se formarem, $133(71,6 \%)$ discentes não pretendem trabalhar na Estratégia Saúde da Família. Do total de entrevistados, 170 (89,5\%) discentes manifestam o desejo de trabalhar tanto no sistema público, quanto no privado. 
TABela 1

Caracterização do perfil sociodemográfico dos discentes do internato da Faculdade de Medicina da Universidade Federal de Goiás. Goiânia, 2012

\begin{tabular}{|c|c|c|c|c|}
\hline \multirow{2}{*}{ Variáveis } & \multirow[t]{2}{*}{$\mathrm{n}$} & \multirow[t]{2}{*}{$\%$} & \multicolumn{2}{|c|}{ IC (95\%) } \\
\hline & & & Mínimo & Máximo \\
\hline \multicolumn{5}{|l|}{ Série } \\
\hline $5^{\mathrm{o}}$ ano & 87 & 46,0 & 0,387 & 0,529 \\
\hline $6^{\mathrm{o}}$ ano & 103 & 54,0 & 0,471 & 0,613 \\
\hline \multicolumn{5}{|l|}{ Sexo } \\
\hline Masculino & 102 & 53,7 & 0,466 & 0,608 \\
\hline Feminino & 88 & 46,3 & 0,392 & 0,534 \\
\hline \multicolumn{5}{|l|}{ Estado civil } \\
\hline Casado & 10 & 5,3 & 0,021 & 0,084 \\
\hline Solteiro & 180 & 94,7 & 0,916 & 0,979 \\
\hline \multicolumn{5}{|l|}{ Idade (anos) } \\
\hline $20-25$ & 129 & 67,9 & 0,613 & 0,745 \\
\hline $25-30$ & 61 & 32,1 & 0,255 & 0,387 \\
\hline \multicolumn{5}{|c|}{ Renda familiar (SM) } \\
\hline 1 a 5 & 18 & 9,5 & 0,053 & 0,136 \\
\hline 6 a 10 & 47 & 24,7 & 0,186 & 0,309 \\
\hline 11 a 15 & 35 & 18,4 & 0,129 & 0,235 \\
\hline 16 a 20 & 25 & 13,2 & 0,084 & 0,180 \\
\hline Acima de 20 & 65 & 34,2 & 0,275 & 0,410 \\
\hline \multicolumn{5}{|c|}{ Filho(a) de médico(a) } \\
\hline Sim & 32 & 16,8 & 0,115 & 0,222 \\
\hline Não & 158 & 83,2 & 0,778 & 0,885 \\
\hline \multicolumn{5}{|c|}{ Algum parente médico } \\
\hline Sim & 117 & 61,5 & 0,547 & 0,685 \\
\hline Não & 73 & 38,5 & 0,315 & 0,453 \\
\hline
\end{tabular}

TABela 2

Expectativas de prática profissional na perspectiva de discentes do internato de Medicina da Universidade Federal de Goiás. Goiânia, 2012

\begin{tabular}{lcccc}
\hline Variáveis & $\mathbf{n}$ & $\%$ & \multicolumn{2}{c}{ IC (95\%) } \\
\hline Perfil do futuro egresso & \multicolumn{5}{c}{ Mínimo } & Máximo \\
\hline Generalista & 23 & 12,1 & 0,075 & 0,167 \\
Especialista & 159 & 83,7 & 0,784 & 0,889 \\
$\quad$ Não opinou & 8 & 4,2 & 0,014 & 0,071 \\
Pretensão de cursar residência médica & & & & \\
Sim & 183 & 96,3 & 0,936 & 0,990 \\
Não & 2 & 1,0 & $-0,004$ & 0,025 \\
Indeciso & 5 & 2,7 & 0,004 & 0,041 \\
Escolha da especialidade & & & & \\
Sim & 111 & 58,4 & 0,514 & 0,654 \\
$\quad$ Não & 10 & 5,3 & 0,021 & 0,084 \\
Indeciso & 69 & 36,3 & 0,295 & 0,432 \\
Pretende trabalhar na ESF & & & & \\
$\quad$ Sim & 54 & 28,4 & 0,220 & 0,348 \\
$\quad$ Não/Só se não passar & & & & \\
$\quad$ na residência Médica & 135 & 71,6 & 0,646 & 0,775 \\
Pretensão futura de trabalho & & & & \\
$\quad$ Somente no sistema público & 5 & 2,6 & 0,004 & 0,049 \\
$\quad$ Somente no sistema privado & 15 & 7,9 & 0,041 & 0,117 \\
Tanto no público como no privado & 170 & 89,5 & 0,851 & 0,938 \\
\hline
\end{tabular}

A percepção do curso de Medicina da FM/UFG pelos discentes do internato aponta um conhecimento superficial das DCN e do PPC por 148 (77,9\%) discentes, enquanto que 42 $(22,1 \%)$ afirmam conhecê-los (Tabela 3$)$.

\section{TABELA 3}

Percepção do curso de Medicina da Universidade Federal de Goiás pelos discentes do internato. Goiânia, 2012

\begin{tabular}{|c|c|c|c|c|}
\hline \multirow{2}{*}{$\begin{array}{l}\text { Variáveis } \\
\text { Conhecimento das DCN } \\
\text { do curso e do PPP }\end{array}$} & \multirow[t]{2}{*}{$\mathrm{n}$} & \multirow[t]{2}{*}{$\%$} & \multicolumn{2}{|c|}{ IC $(95 \%)$} \\
\hline & & & Mínimo & Máximo \\
\hline Sim & 42 & 22,1 & 0,162 & 0,280 \\
\hline Não/Superficialmente & 148 & 77,9 & 0,720 & 0,838 \\
\hline \multicolumn{5}{|c|}{ Percepção da educação médica na FM/UFG } \\
\hline Centrada na Atenção Básica & 39 & 20,5 & 0,148 & 0,263 \\
\hline Centrada no hospital & 139 & 73,2 & 0,669 & 0,793 \\
\hline Não opinou & 12 & 6,3 & 0,029 & 0,098 \\
\hline \multicolumn{5}{|c|}{ Cenários de prática favorecem a formação na Atenção Básica } \\
\hline Sim & 84 & 44,3 & 0,371 & 0,513 \\
\hline Não/Parcialmente & 106 & 55,7 & 0,487 & 0,629 \\
\hline \multicolumn{5}{|c|}{ Contribuição docente para a prática generalista } \\
\hline Sim & 71 & 37,3 & 0,305 & 0,442 \\
\hline Não & 22 & 11,6 & 0,070 & 0,161 \\
\hline Direcionado para especialista & 97 & 51,1 & 0,430 & 0,580 \\
\hline \multicolumn{5}{|c|}{ Grau de satisfação com o curso (escala Lickert) } \\
\hline 1 & 1 & 0,5 & 0,005 & 0,016 \\
\hline 2 & 10 & 5,3 & 0,021 & 0,084 \\
\hline 3 & 54 & 28,5 & 0,220 & 0,348 \\
\hline 4 & 112 & 58,9 & 0,520 & 0,659 \\
\hline 5 & 13 & 6,8 & 0,033 & 0,104 \\
\hline
\end{tabular}

Quanto à percepção dos cenários de prática como facilitadores da formação profissional da Atenção Básica, 84 (44,3\%) discentes os consideram favoráveis; 106 (55,7\%) julgam que tais cenários contribuem apenas parcialmente ou não favorecem a formação profissional na Atenção Básica.

A educação médica na FM/UFG, na perspectiva discente, é percebida como hospitalocêntrica por 139 (73,2\%) discentes, o que é estatisticamente significante $(\mathrm{p}=0,0001)$, enquanto 39 (20,5\%) consideram o curso centrado na atenção básica e 12 $(6,3 \%)$ não responderam a questão.

O grau de satisfação com o curso, avaliado pela escala Likert de 5 pontos, na qual 1 significa totalmente insatisfeito e 5 significa totalmente satisfeito, demonstrou que $125(65,7 \%)$ discentes estão satisfeitos sendo que, destes, 13 (6,8\%) afirmam estar completamente satisfeitos.

\section{DISCUSSÃO}

O perfil sociodemográfico de discentes do internato do curso de Medicina da FM/UFG é composto por indivíduos com 
média de idade de 23,8 anos, solteiros, com carro próprio, o que demonstra um nível socioeconômico elevado, fruto de um modelo excludente e elitista do vestibular universal convencional existente na época de ingresso desses estudantes. Recentes políticas públicas de cotas de ingresso para estudantes de escolas públicas, negros, índios e outras minorias poderão reverter este quadro no futuro ${ }^{20-22}$.

As expectativas de prática profissional demonstradas nos resultados aqui apresentados apontam na direção de um egresso especialista, via residência médica, sem a pretensão primária de trabalhar na atenção básica. Na análise dos dados, percebe-se que os discentes veem na ESF um plano alternativo, ou seja, um meio de subsistência a ser usado apenas se não forem aprovados no concurso para residência médica, não a percebendo como uma meta-fim, o que contraria o preconizado nas DCN e no PPC da instituição ${ }^{12,14,30}$.

É importante salientar que uma parcela estatisticamente significativa de discentes percebe o curso de Medicina da UFG ainda hospitalocêntrico, embora o PPC contemple uma estratégia de (des)hospitalização progressiva e multiplicidade dos cenários de prática ${ }^{7,9,18}$. A dissociação ensino/serviço tem sido apontada como a responsável pela manutenção do modelo de ensino hospitalocêntrico ${ }^{3,22}$.

Uma parte expressiva de discentes afirma não ter conhecimento adequado das DCN, nem do PPC do seu curso, o que encontra paralelo na literatura nacional ${ }^{3,9,26}$.

Os discentes consideram que os professores, em sua maioria, são tendenciosos pela especialização, fazendo com que os alunos optem por ela, promovendo um direcionamento precoce nos anos da graduação $7,12,22,30$.

Em verdade, os alunos tendem a copiar os modelos vivenciados pelos professores, que são cruciais na formação dos graduandos. A resistência dos docentes tem sido um entrave às mudanças efetivas necessárias à implementação das propostas das Diretrizes Curriculares Nacionais para o curso de graduação em Medicina ${ }^{12,20,30}$.

\section{CONCLUSÃO}

Os discentes do internato da FM/UFG pretendem, após se formarem, ser médicos especialistas, cursar residência médica e, a priori, não têm intenção de trabalhar na Estratégia Saúde da Família. Eles expressam o desejo de trabalhar tanto no serviço público quanto no privado.

A pesquisa demonstrou que há uma dissonância entre o perfil do egresso pretendido tanto pelas DCN quanto pelo PPC da instituição e as expectativas de prática profissional dos discentes do internato da instituição de ensino superior em que ocorreu a pesquisa.
O perfil sociodemográfico desses alunos é caracterizado principalmente por indivíduos com idade média de 23,8 anos, solteiros, sem filhos, com nível socioeconômico elevado.

\section{REFERÊNCIAS}

1. Moraes VA, Pereira EDR, Naghettini AV. Quais e Como Deve Ser os Cenários de Ensino-Aprendizagem Segundo o Perfil do Egresso Proposto nas Diretrizes Curriculares Nacionais. In: Streit D, Barbosa Neto F, Lampert J, Lemos JM, Batista N. Educação Médica: 10 Anos de Diretrizes Curriculares Nacionais. Rio de Janeiro: ABEM; 2012. p. 143-63.

2. Universidade Federal de Goiás. Faculdade de Medicina. Projeto Político Pedagógico do Curso de Medicina. Goiás: UFG; 2003.

3. Oliveira NA, Meirelles RMS, Cury GC, Alves LA. Mudanças Curriculares no Ensino Médico Brasileiro: Um Debate Crucial no Contexto do Promed. Rev Bras Educ Med. 2008;32(3):333-46. DOI: http:/ /dx.doi.org/10.1590/S010055022008000300008 .

4. Ruiz DG, Farenzena GJ, Haeffner LSB. Internato Regional e Formação Médica: Percepção da Primeira Turma Pós-Reforma Curricular. Rev Bras Educ Med. 2010; 34(1):21-27. DOI: http://dx.doi.org/10.1590/S010055022010000100004.

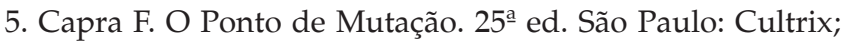
2006. p.116-55.

6. Ceccim RB, Feuerwerker LCM. Mudanças na Graduação das Profissões de Saúde sob o Eixo da Integralidade. Cad Saúde Pública. 2004;20(5):1400-10. DOI: http://dx.doi. org/10.1590/S0102-311X2004000500036.

7. Lampert JB. Tendências de Mudanças na Formação Médica no Brasil: Tipologia das Escolas, 2ª ed. São Paulo: Hucitec/ABEM; 2009.

8. Borges JLG, Carnielli BL. Educação e Estratificação Social no Acesso à Universidade Pública. Cad Pesquisa. 2005;35:124. DOI: http://dx.doi.org/10.1590/S010015742005000100007.

9. Brasil. Ministério da Educação. Conselho Nacional de Educação. Câmara de Educação Superior. Resolução CNE/CES n. ${ }^{\circ}$ 4, de 7 de novembro de 2001. Institui diretrizes curriculares nacionais do curso de graduação em medicina. Diário Oficial da União. Brasília, 9 nov. 2001; Seção 1, p.38.

10. Brasil. Conselho Federal de Medicina. Demografia Médica. São Paulo; 2012.

11. Paim J, Travasos C, Almeida C, Bahia L, Macinko J. O Sistema de Saúde Brasileiro: História, Avanços e Desafios. Lan- 
cet [periódico na internet]. 2011 [acesso em 1 nov. 2012];1121. Disponível em: http://download.thelancet.com/flatcontentassets/pdfs/brazil/brazilpor1.pdf.

12. Streit DS, Neto Barbosa F, Lampert J, Lemos JM, Batista N, orgs. Educação Médica: 10 Anos de Diretrizes Curriculares Nacionais. Rio de Janeiro: ABEM; 2012.

13. Ceccim RB, Feuerwerker LCM. O Quadrilátero de Formação para a Área de Saúde. PHYSIS: Rev Saúde Coletiva. 2004;14(2):41-65.

14. Lampert JB, Perim GL, Aguilar-da-Silva RH, Stella RCR, Abdala IG, Costa NMSC. O mundo do trabalho no contexto da formação médica. Rev Bras Educ Med. 2009; 33(1):35-43. DOI: http://dx.doi.org/10.1590/S010055022009000500004 .

15. Arcoverde TL. Formação Médica: (Des)Construção do Sentido da Profissão-Trajetória da Representação Social. Rev Bras Educ Med. 2007;31(2):191. DOI: http://dx.doi. org/10.1590/S0100-55022007000200013.

16. Feuerwerker LCM. A Formação dos Médicos Especialistas e a Residência Médica no Brasil. Saúde Debate. 2001;25(57):39-54.

17. Godefrooij MB, Diemers AD, Scherpbier AJJA. Student's Perceptions about the Transition to the Clinical Phase of a Medical Curriculum with Preclinical Patient Contacts; a Focus Group Study. BMC Med Educ [periodico na internete]. 2010 [acesso em 27 fev. 2012];10:28. Disponível em: http / / www.biomecentral.com/1372-6920/10/28.

18. Perim GL. Avaliação da Educação Superior: Uma Realidade na Educação Médica. Campinas; 2007. Doutorado [Tese] - Universidade Estadual de Campinas . Faculdade de Educação.

19. Almeida Filho N. Reconhecer Flexner: Inquérito sobre Produção de Mitos na Educação Médica no Brasil Contemporâneo. Cad Saúde Pública. 2010;26(12):2234-49. DOI: http:/ /dx.doi.org/10.1590/S0102-311X2010001200003.

20. Ferreira CR, Fiorini VML, Crivelaro E. Formação Profissional no SUS, O Papel da Atenção Básica na Perspectiva Docente. Rev Bras Educ Med. 2010;34(2):207-15. DOI: http:/ / dx.doi.org/10.1590/S0100-55022010000200004.

21. Fiorotti KP, Rossoni RR, Miranda AE. Perfil do Estudante de Medicina da Universidade Federal do Espírito Santo, 2007. Rev Bras Educ Med. 2010;34(3):335-62. DOI: http:/ / dx.doi.org/10.1590/S0100-55022010000300004.

22. Oliveira NA, Alves LA. Ensino Médico, SUS e Início da Profissão: Com se Sente Quem Está se Formando? Rev Bras Educ Med. 2011;35(1):26-36. DOI: http://dx.doi. org/10.1590/S0100-55022011000100005.
23. Ribeiro MMF, Leal SS, Diamantino FC, Bianchi HA. A Opção pela Medicina e os Planos em Relação ao Futuro Profissional de Estudantes de uma Faculdade Pública Brasileira. Rev Bras Educ Med. 2011;35(3):405-11. DOI: http:/ /dx.doi. org/10.1590/S0100-55022011000300015.

24. Novaes MRCG, Novaes LCG, Guilhem D, Stepke FL, Silveira CCC, Trindade EMV, et al. Atitudes Éticas dos Estudantes e Egressos de Medicina de um Curso com Metodologias Ativas. Rev Bras Educ Med. 2010;34(1):43-56. DOI: http:/ /dx.doi.org/10.1590/S0100-55022010000100006.

25. Ferreira RA, Peret Filho LA, Goulart EMA, Valadão MMA. Estudantes de Medicina da Universidade Federal de Minas Gerais. Rev Assoc Med Bras. 2000;46(3):224-31. DOI: http:/ /dx.doi.org/10.1590/S0104-42302000000300007.

26. Tavares AP, Ferreira RA, França EB, Fonseca Junior CA, Lopes GC, Dantas NGT, Cardoso SAV. O Currículo Paralelo dos Estudantes de Medicina da UFMG. Rev Bras Educ Med. 2007;31(3):254-65. DOI: http://dx.doi.org/10.1590/ S0100-55022007000300008.

27. Shadbolt N, Bunker J. Choosing Geral Pratice, Australian Farmacology Physiology. 2009;38(1):53-5.

28. Sakai MA. Teste de Progresso e Avaliação do Curso: Dez Anos de Experiência da Medicina da Universidade Federal de Londrina. Rev Bras Educ Med. 2008;32(2):254-63. DOI: http:/ /dx.doi.org/10.1590/S0100-55022008000200014.

29. Brasil. Ministério da Saúde. Coordenação Geral de Políticas de Recursos Humanos. Programa de Incentivo às Mudanças Curriculares para as Escolas Médicas (PROMED). Brasília; 2002. p.40.

30. Abreu Neto IP, Lima Filho OS, Silva LEC, Costa NMSC. Percepção dos Professores sobre o Novo Currículo de Graduação da Faculdade de Medicina da UFG Implantado em 2003. Rev Bras Educ Med. 2006;30(1): 154-160. DOI: http:/ /dx.doi.org/10.1590/S0100-55022006000300006.

\section{CONTRIBUIÇÃO DOS AUTORES}

Marcos Augusto Filisbino Elaboração do projeto de pesquisa, criação do desenho do estudo, realização da coleta de dados, tratamento estatístico dos dados, elaboração da versão inicial e final do artigo. Vardeli Alves Moraes contribuição na concepção do desenho do estudo, na elaboração do TCLE, revisão crítica e participação da elaboração final do artigo.

\section{CONFLITO DE INTERESSES}

Declarou não haver. 


\section{ENDEREÇO PARA CORRESPONDÊNCIA}

Marcos Augusto Filisbino

Universidade Federal de Goiás - Faculdade de Medicina -

Departamento de

inecologia e Obstetrícia.

Primeira Avenida, s/n

Universitário - Goiânia

CEP. 74605-050 GO

E-mail: marcosfilisbino@hotmail.com 